\title{
Desmoid-type fibromatosis involving the brachial plexus
}

\author{
Joshua Seinfeld, M.D., Bette K. KLeinsChmidt-DeMasters, M.D., \\ Shalini Tayal, M.D., AND KeVIN O. LILLEHEI, M.D. \\ Departments of Neurosurgery, Neurology, and Pathology, University of Colorado Health \\ Sciences Center, Denver, Colorado
}

\begin{abstract}
$\checkmark$ Desmoid-type fibromatosis involving the brachial plexus is a rare and challenging disease. Due to involvement of crucial neurovascular structures, wide local excision of the associated fibromas is rarely feasible and recurrence is common. The authors describe their experience in four surgically treated patients with desmoid-type fibromatosis involving the brachial plexus and review the relevant neurosurgical literature.

All tumors were assessed for $c$-KIT oncogene mutations in hopes of establishing a biological basis for using the tyrosine kinase inhibitor imatimib mesylate as an adjuvant therapy. Three patients experienced tumor recurrence requiring reoperation. Fractionated radiotherapy achieved local control in three patients, and the disease in one patient progressed beyond the treatment field. Single base pair changes at exon 10 of the $c$-KIT oncogene were identified in three tumors. One tumor with this mutation did not respond to treatment with imatimib mesylate. A review of the literature revealed 17 additional patients in two different case series. Analysis of these cases emphasizes the need for careful resection in patients with desmoid-type fibromatosis and supports the conclusion that without adjuvant radiotherapy a high local recurrence rate can be anticipated. For optimal local disease control, the authors recommend postsurgical radiation therapy regardless of the extent of resection achieved. The mutational status of the $c$ KIT oncogene remains an intriguing biological marker that in the future may predict which lesions will be responsive to imatimib mesylate; larger series will be necessary to test this hypothesis.
\end{abstract}

KEY WORDS - brachial plexus tumor - $c$-KIT - desmoid-type fibromatosis • imitimab mesylate - radiation therapy

$\mathrm{F}$ IRST DESCRIBED IN THE abdominal wall of pregnant or recently pregnant women, desmoid-type fibromatosis has since been reported arising in all regions of the body. ${ }^{2}$ Over the years many terms have been used to refer to this entity, including fibromatosis, desmoid tumors, fibromatosis, and aggressive fibromatosis. "Desmoid-type fibromatosis" has emerged as the designation of choice by the World Health Organization, however. ${ }^{10}$ Although classified as monoclonal proliferations arising from musculoaponeurotic structures, these lesions have long been noted to be locally aggressive and often recur after resection..$^{11,13,24}$ Although multiple intra- and extraabdominal lesions can be associated with the autosomaldominant familial adenomatous polyposis variant known as Gardner syndrome or other familial syndromes, most cases encountered by the neurosurgeon are solitary and sporadic. 5,23

Desmoid-type fibromatoses arising in the neck and su-

Abbreviations used in this paper: GTR = gross-total resection; $\mathrm{MR}=$ magnetic resonance. praclavicular region are often adjacent to or encasing crucial neurovascular structures including the brachial plexus making wide local excision with microscopically negative margins unfeasible without unacceptable morbidity. Despite the challenge these lesions present both at surgery and in choosing what adjuvant therapies should be used, surprisingly little neurosurgical literature exists devoted to this topic. In 2006 we reported our experience with four cases of desmoid-type fibromatosis involving the brachial plexus. In addition, we assessed these lesions for mutations in the $c-K I T$ oncogene in hopes of establishing a basis for predicting which of these lesions would respond to the chemotherapy agent imantinib mesylate. We also performed a review of the existing literature in an attempt to identify the most efficacious adjuvant treatment regimen. ${ }^{25}$

Here, using additional data obtained since our initial report, we aim to readdress the management of these lesions with an emphasis on the application of adjuvant therapies. Given the high rate of recurrence and local invasiveness associated with desmoid-type fibromatosis it is 
important that neurosurgeons be familiar with their natural history and treatment options in order to provide optimal local control.

\section{Material and Methods}

We retrospectively reviewed the charts of the four patients with sporadic desmoid-type fibromatosis involving the brachial plexus treated at our institution..$^{25}$ These patients included three women and one man who ranged in age from 42 to 57 years at the time of presentation. Polymerase chain reaction analysis was used to amplify and sequence exons $9,10,11$, and 17 of the $c$-KIT oncogene to search for mutations in each of these tumors using techniques described in our previous publication. ${ }^{25} \mathrm{~A}$ literature search was also performed with the OVID search engine using terms such as "desmoid," "desmoid tumor," and "desmoid-type fibromatosis" in conjunction with "plexus," "brachial plexus," or "peripheral nerve" to find relevant case series and review articles.

\section{Results}

All four patients with desmoid-type fibromatosis involving the brachial plexus treated at the University of Colorado are still living after a mean follow-up period of 57 months. In all patients, the tumor was noted to be originating from the scalene musculature at the time of the initial operation. Using a meticulous dissection technique, the neurovascular elements were first identified and examined to determine the involvement by tumor prior to resection of the lesion (Fig. 1). Gross-total excision was achieved at all initial operations and all repeated operations. Three of the four patients required repeated operation for tumor recurrence, and no patient has gone on to undergo a third surgery.

The presenting symptoms in this cohort included a palpable mass in all four cases, localized tenderness and pain in the region of the mass in two cases, and mild deltoid, triceps, and biceps weakness (Grade 4/5) in one case. In all four patients initial MR imaging revealed an enhancing mass involving the brachial plexus (Fig. 2).

\section{Radiation Therapy}

Fractionated radiation therapy totaling 50 to 54 Gy was delivered in all four cases. In two cases radiation therapy was started empirically shortly after the initial operation, while in the two earlier cases it had been delayed until after tumor recurrence and repeated operation, reflecting a change in our practice habits. In only one patient has tumor progression occurred after radiation therapy, and in this patient the tumor is felt to have recurred outside the radiation field.

\section{Chemotherapeutic Agents}

Chemotherapeutic agents were used in two cases. Tamoxifen was used twice - once after the initial surgery and once following recurrence after repeated operation. In both cases tumor growth occurred during therapy though in one case tumor size was noted to be stable on followup MR images for 12 months. Imatimib mesylate was used in one case after tumor recurrence was noted follow- ing two surgeries and fractionated radiation. Increase in tumor size was noted over nine months of therapy and the patient was subsequently switched to tamoxifen.

Surgical complications in this series include one case of hemidiaphragm paralysis following an initial operation (which has since resolved after 24 months of follow-up) and two cases following reoperation. In only one of three cases was hemidiaphragm paralysis mildly symptomatic otherwise it was only apparent radiographically. One patient reported new subjective tightness in the field of radiation without any subjective deficits. No new sensorimotor deficits occurred during therapy or follow-up.

\section{Pathological Characteristics}

Histologically, all lesions had a similar appearance, with plump tapering fibroblastic-appearing cells and collagen deposition (Fig. 3A and B). All lesions had scant mitotic activity, far less than the $5 / 10 \mathrm{hpf}$ used to classify a lesion as a low-grade fibrosarcoma. ${ }^{3}$ In all cases tumor infiltration was present at the edge of the resected area, suggesting microscopic subtotal resection. In three of four cases the tumor contained occasional elongated cells that stained positive for S100 protein (polyclonal; Dako Corp.) (Fig. 3C). This has been previously noted in desmoid-type fibromatoses, and can make the pathological distinction from neurofibroma challenging without clinical correlation. ${ }^{6}$ In all four tumors, sporadic cells were also weakly immunoreactive for c-KIT (CD117) (polyclonal, Dako Corp.)

\section{Mutational Status of c-KIT}

In the analysis of these tumors for a mutation in the $c$ $K I T$ oncogene, we identified a single base pair change in exon 10 in three of four cases. In two tumors this consisted of a base pair change at codon 541 (A to C) resulting in an amino acid change from methionine to leucine and in one tumor a base pair change at codon 546 (A to G) without any amino acid change. The tumor of the one patient that received imitimab mesylate exhibited the A to $\mathrm{C}$ base pair change at codon 541 .

\section{Literature Review}

A review of the literature identified two case series reporting treatment of desmoids tumors involving the brachial plexus. The first series, reported by Gaposhkin et al., ${ }^{9}$ and reviewed in our original publication ${ }^{25}$ is included in our aggregate series seen in Table 1 . The second case series reported by Ganju and colleagues ${ }^{8}$ includes six patients undergoing surgical treatment for desmoids tumors at Louisiana State University Health Sciences Center. Age, sex, site of tumor origin, prior therapy, extent of resection, postoperative status, and duration of follow-up are reported. These patients have been reported in the series summarized in Table 1 . None of these patients had undergone prior chemotherapy or radiation. Unfortunately no information is available concerning subsequent adjuvant therapy.

\section{Discussion}

Despite the challenges that desmoid-type fibromatosis involving the brachial plexus pose there is very little neu- 


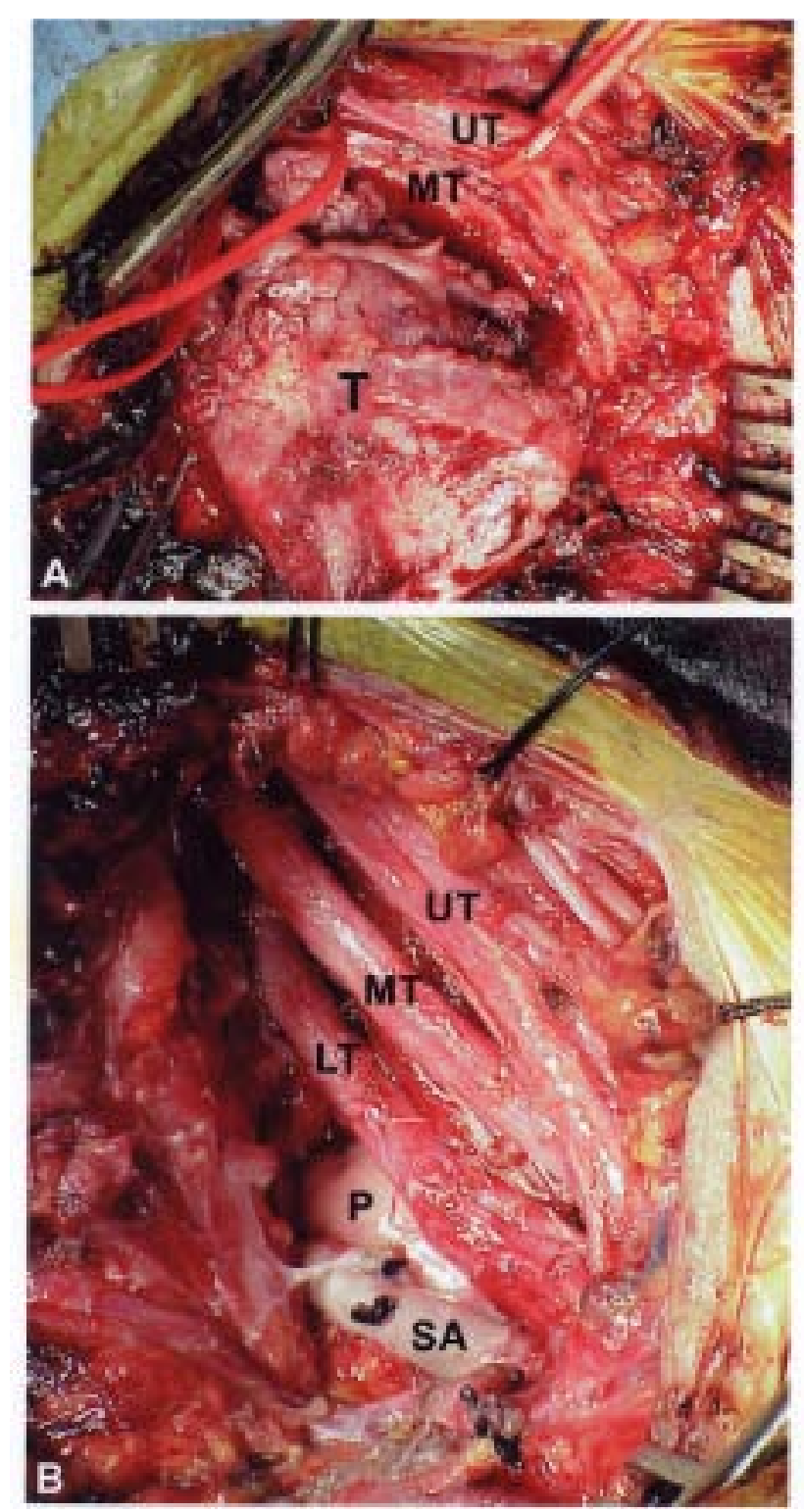

FIG. 1. Intraoperative photographs showing the site of GTR of desmoid-type fibromatoses involving the brachial plexus. A: The desmoid tumor (T) and displacement of the upper trunk (UT) and middle trunk (MT) of the brachial plexus are shown. B: After GTR of the tumor, all trunks of the brachial plexus (including the lower trunk [LT]) as well as the pleura (P) and subclavian artery (SA) are visible. (Reprinted with permission from Seinfeld et al.: $\mathbf{J}$ Neurosurg 104:749-756, 2006.)

rosurgical literature devoted to this topic. Although trauma and prior surgical procedures leading to scar formation have been previously identified as risk factors for the formation of desmoid-type fibromatoses, to our knowledge only one other case series exists in the neurosurgical literature that addresses nonfamilial adult desmoid-type fibromatosis. ${ }^{7,9,12,16,22}$

Extraabdominal desmoid-type fibromatosis has been reported to be 1.5 to 3 times more common in women and occurs with an incidence of 0.2 to 0.4 tumors per 100,000 people/year making them fairly common soft tissue
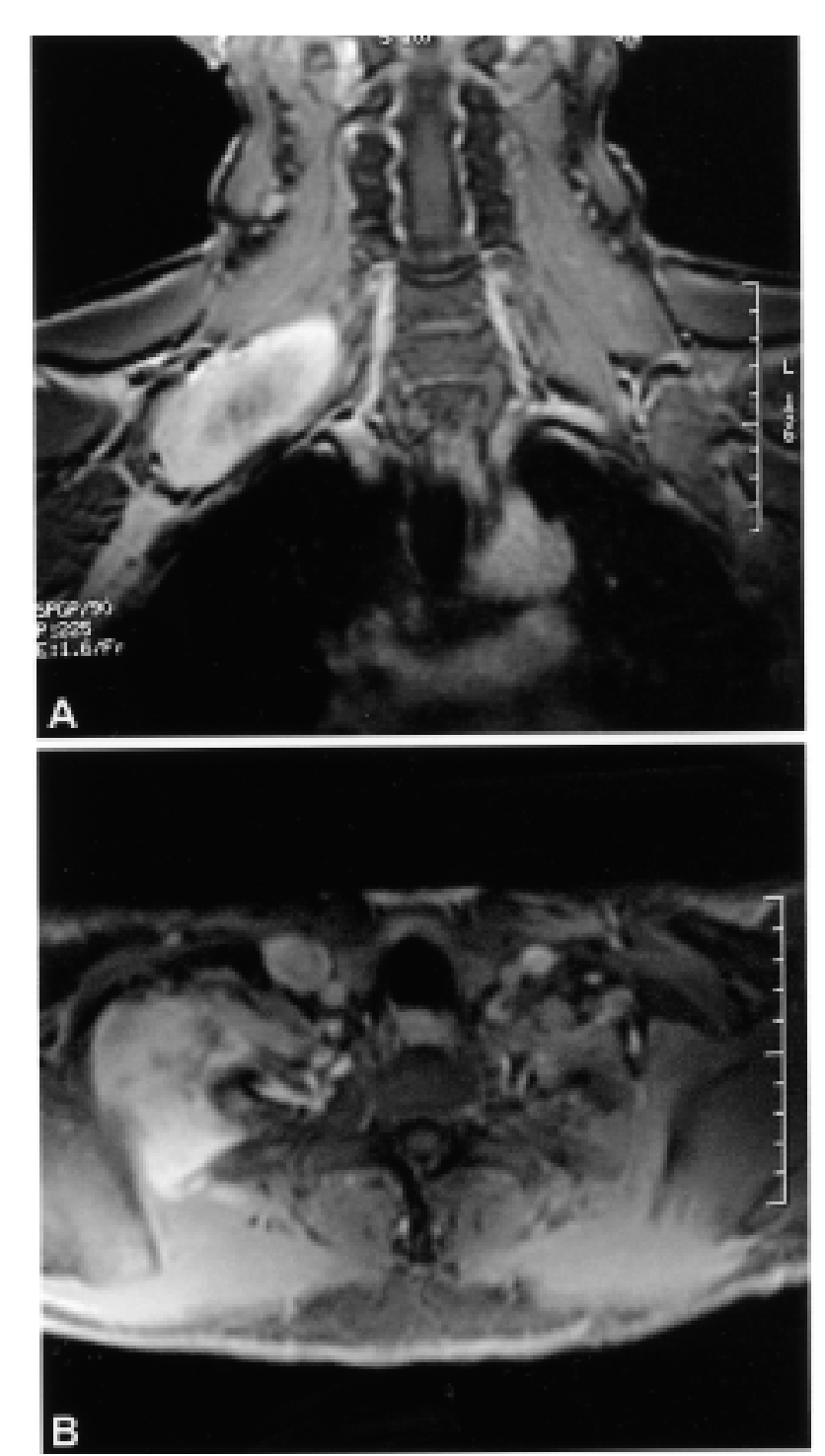

FIG. 2. Gadolinium-enhanced MR images revealing a supraclavicular mass within the region of the brachial plexus. A: Coronal T1-weighted MR image revealing an $8.5 \times 3.5-\mathrm{cm}$ mass within the region of the brachial plexus. B: Axial T1weighted MR image demonstrating the difficulty in separating the tumor from the elements of the brachial plexus and the scalene musculature. (Reprinted with permission from Seinfeld et al.: J Neurosurg 104:749-756, 2006.)

tumors. ${ }^{10,12,21,22}$ Our series is consistent with these statistics as three of our patients are female. The head and neck region (especially supraclavicular region) is the most common extraabdominal site for these lesions, accounting for 9 to $35 \%$ of the cases of extraabdominal desmoid-type fibromatosis. It is therefore fitting that these lesions represented the most common benign tumor involving the brachial plexus in a series of 146 nonneural sheath nerve tumors reported by Kim et al. ${ }^{15}$ in 2005 . In their series, desmoid tumors accounted for six of 33 tumors involving the brachial plexus.

Obtaining local control of these tumors is problematic. In the four cases treated at the University of Colorado, 
GTR was obtained in all cases, albeit with microscopic positive tumor margins. The surgeries were performed while focusing on the preservation of the surrounding neurovascular structures. Our high local recurrence rate of 75\% after initial resection is consistent with the existing literature. Recurrence rates for dermoid-type fibromatoses, even with wide resection, an improbability when dealing with the brachial plexus, range from 24 to $77 \%$. Because of the locally aggressive nature of the these tumors many clinicians place them in the same category as low-grade fibrosarcomas. It is important to realize, however, that desmoid-type fibromatoses do not have the potential to metastasize to different sites or degenerate into higher-grade malignancies. ${ }^{2,8,12}$

It is also important to distinguish desmoid-type fibromatoses from nerve sheath tumors such as schwannomas and neurofibromas because of their different natural histories and need for postsurgical therapies. If the tumor is noted to arise from musculoaponeurotic structures, the pathologist should be informed as this will increase the likelihood of the correct diagnosis being made on frozen and permanent sections. In extraabdominal locations, the diagnosis of desmoid-type fibromatosis is less likely to be entertained and in some instances may have considerable overlap with neurofibroma, such as the presence of wavy tumor nuclei, focal myxoid change, and occasional S100 protein immunoreactivity. ${ }^{6}$ This dilemma was illustrated in two of our cases. During frozen section examination of one of our cases the neuropathologist was only able to render a differential diagnosis of neurofibroma or desmoid-type fibromatosis until the site of tumor origin was specified. In another case, the patient underwent a second resection at another large referral center for tumor recurrence after initial resection and diagnosis at the University of Colorado. At the time of this second procedure, the histological features of the tumor prompted the diagnosis of neurofibroma until the site of origin was specified by the neurosurgeon.

Our previous experience with treatment of plexal tumors has enabled us to successfully avoid the creation of new neurological deficits in our patients, with the exception of phrenic nerve injury resulting in hemidiaphragm paralysis. This complication occurred in one patient after the initial surgery and in two other patients after the second operation. Interestingly, in the only patient in whom hemidiaphragm dysfunction was symptomatic and manifested by mild dyspnea on exertion, phrenic nerve function was recovered. In the other two case series addressing desmoid-type fibromatoses of the brachial plexus, this complication was not commented on. ${ }^{8,9}$ It is plausible that this omission may be indicative of the rarity of symptomatic hemidiaphragm paralysis as it may often only be noticed on careful radiographic review of plain chest films.

Our initial strategy when we began encountering these tumors in the mid-1990s was to proceed with the best possible resection and limit fractionated radiotherapy in cases of tumor recurrence. This approach was later altered as a result of the tumor recurrences that have occurred in three of our four patients. We now favor proceeding with radiotherapy at a total dose of 50 to 54 Gy after the initial surgery. Authors of studies of desmoid-type fibromatoses occurring in nonneurosurgical locations have suggested

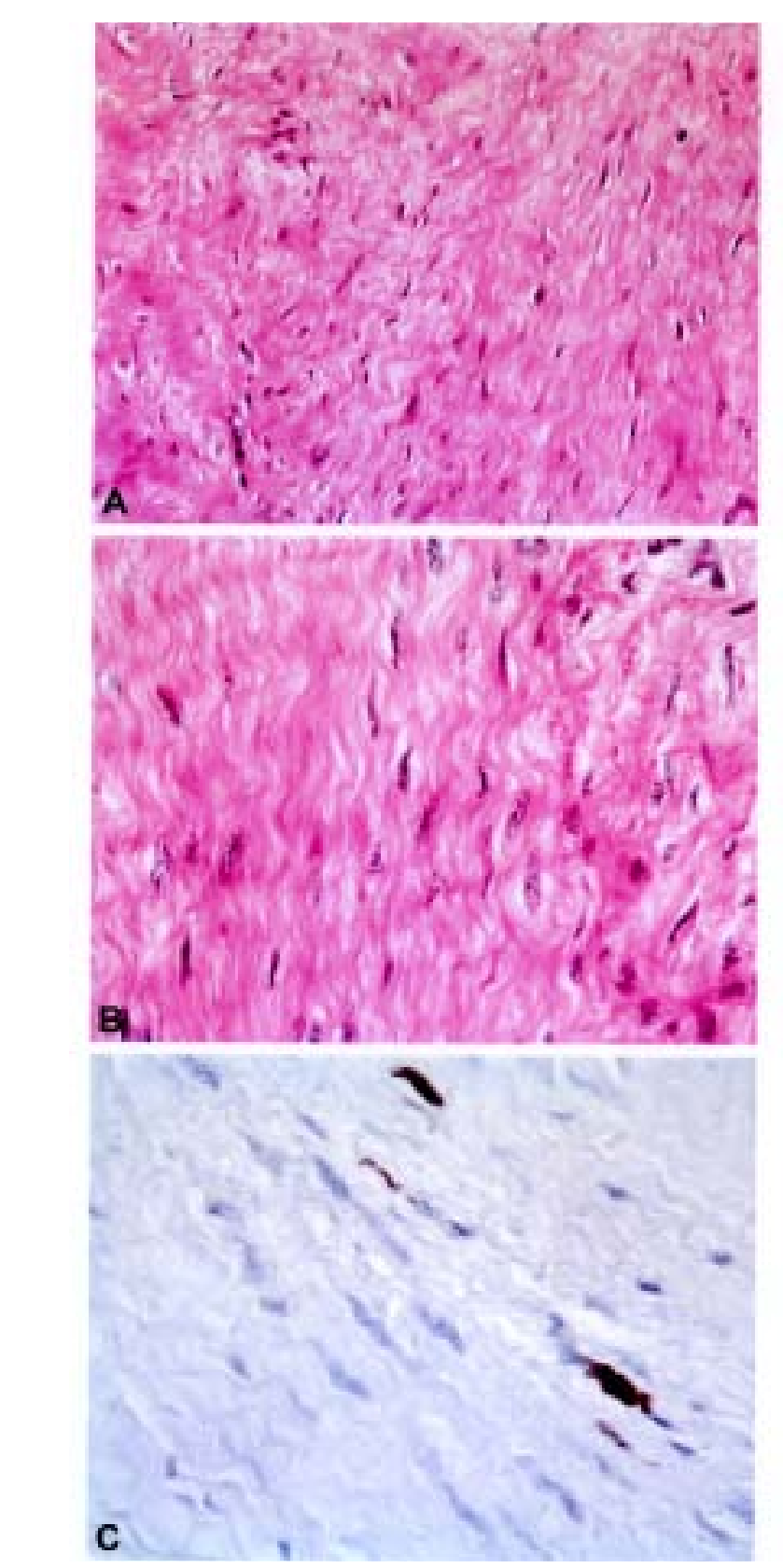

FIG. 3. Photomicrographs of tissue from desmoid-type fibromatoses. A and B: Desmoid-type fibromatoses show variable cell density and collagen deposition and are composed of plump to tapering spindle cells with bland cytological features but some degree of wavy nuclear features. C: Three of the four cases showed occasional elongated cells that were immunoreactive for $\mathrm{S}$ 100 protein. $\mathrm{H} \& \mathrm{E}$ (A and B) and anti-S100 staining (C), original magnification $\times 200(\mathrm{~A})$ and $\times 400(\mathrm{~B}$ and C). (Reprinted with permission from Seinfeld et al.: J Neurosurg 104:749-756, 2006.)

that radiation therapy with or without surgery offers improved local control. ${ }^{11,13,14,22}$ Nuytten and colleagues ${ }^{19}$ in a review of 22 series from the literature, found a local control rate of $75 \%$ with surgery and radiation therapy, $78 \%$ with radiation alone, compared with $61 \%$ with surgery alone. In 2006, Wang et al. ${ }^{27}$ published their experience with 24 desmoid tumors of the head and neck and en- 
TABLE 1

Clinical characteristics in 21 patients with desmoid-type fibromatoses involving the brachial plexus*

\begin{tabular}{|c|c|c|c|c|c|c|}
\hline Center $\dagger$ & $\begin{array}{l}\text { Age (yrs), } \\
\text { Sex }\end{array}$ & Tumor Type & $\begin{array}{l}\text { GTE } \\
(y / n)\end{array}$ & Radiation (Gy) & Time to Recurrence (mos) & $\begin{array}{c}\text { Follow } \\
\text { Up (mos) }\end{array}$ \\
\hline \multirow[t]{2}{*}{$\mathrm{UCH}$} & $48, \mathrm{~F}$ & primary & $\mathrm{y}$ & none & 12 & 48 \\
\hline & & recurrence & $\mathrm{y}$ & 54 & none & \\
\hline \multirow[t]{2}{*}{$\mathrm{UCH}$} & $57, \mathrm{~F}$ & primary & $\mathrm{y}$ & none & 18 & \\
\hline & & recurrence & $\mathrm{y}$ & 50 & none & 48 \\
\hline \multirow[t]{2}{*}{$\mathrm{UCH}$} & $42, \mathrm{~F}$ & primary & $\mathrm{y}$ & 54 & 37 & 67 \\
\hline & & recurrence & $\mathrm{y}$ & none & 6 (treated w/ chemotherapy) & \\
\hline $\mathrm{UCH}$ & $50, \mathrm{M}$ & primary & $\mathrm{y}$ & 50 & none & 11 \\
\hline MSKCC & $34, \mathrm{~F}$ & primary & $\mathrm{y}$ & 60 & none & 48 \\
\hline MSKCC & $19, \mathrm{~F}$ & recurrence & $\mathrm{y}$ & NR & none (eight previous resections) & 75 \\
\hline \multirow[t]{2}{*}{ MSKCC } & $63, \mathrm{M}$ & primary & $\mathrm{y}$ & 50 & 25 & 34 \\
\hline & & recurrence & $\mathrm{y}$ & none & none & \\
\hline \multirow[t]{2}{*}{ MSKCC } & $51, \mathrm{M}$ & primary & $\mathrm{y}$ & 56 & 8 & 130 \\
\hline & & recurrence & $\mathrm{y}$ & none & none & \\
\hline \multirow[t]{4}{*}{ MSKCC } & $30, \mathrm{M}$ & primary & $\mathrm{y}$ & 92 (brachytherapy) & 12 & 86 \\
\hline & & recurrence & $\mathrm{y}$ & none & 16 & \\
\hline & & recurrence & $\mathrm{y}$ & none & 29 & \\
\hline & & recurrence (forequarter amputation) & $\mathrm{n}$ & none & none & \\
\hline MSKCC & $65, \mathrm{M}$ & primary & $\mathrm{y}$ & 60 & none & 52 \\
\hline MSKCC & $23, \mathrm{~F}$ & primary & $\mathrm{n}$ & 65 & persistent disease & 99 \\
\hline MSKCC & $58, \mathrm{M}$ & primary & $\mathrm{y}$ & none & none & 53 \\
\hline MSKCC & $54, \mathrm{~F}$ & primary & $\mathrm{y}$ & 45 & none & 112 \\
\hline MSKCC & $76, \mathrm{~F}$ & primary & $\mathrm{y}$ & 45 (brachytherapy) & none & 26 \\
\hline MSKCC & $29, \mathrm{M}$ & primary & $\mathrm{n}$ & 60 & persistent disease & 17 \\
\hline LSUHSC & $67, \mathrm{~F}$ & primary & $\mathrm{y}$ & NR & NR & 27 \\
\hline LSUHSC & $58, \mathrm{M}$ & primary & $\mathrm{y}$ & NR & NR & 58 \\
\hline LSUHSC & $37, \mathrm{~F}$ & primary & $\mathrm{y}$ & NR & NR & 24 \\
\hline LSUHSC & $56, \mathrm{~F}$ & recurrence & $\mathrm{n}$ & NR & NR & 92 \\
\hline LSUHSC & $58, \mathrm{~F}$ & recurrence (forequarter amputation) & $\mathrm{n}$ & NR & NR & 116 \\
\hline LSUHSC & $46, \mathrm{M}$ & primary & $\mathrm{n}$ & NR & NR & 2 \\
\hline
\end{tabular}

* GTE $=$ Gross-total excision; LSUHSC $=$ Louisiana State University Health Sciences Center MSKCC = Memorial Sloan-Kettering Cancer Center; NR = not reported; UCH = University of Colorado Hospital.

$\dagger$ Cases from University of Colorado Hospital are described in this paper. Cases from Memorial Sloan-Kettering Cancer Center have been reported by Gaposchkin et al., and those from LSUHSC were reported by Ganju et al. Table adapted from Seinfeld et al.: $\mathbf{J}$ Neurosurg 104:749-756, 2006 .

dorsed surgery with repeated resection as necessary without empiric adjuvant radiotherapy. These authors cite good local tumor control and low morbidity associated with reoperation as reasons not to expose patients to the potential side effects of radiotherapy. As this time we disagree with this strategy based on our experience and the bulk of the literature that suggests that radiation is a key component in achieving local control, and is generally well-tolerated by the patient (no side effects were noted in our patients except for one case of subjective tightness in the treatment field).

To our knowledge the only other two case series in the literature devoted to low-grade soft tissue tumors involving the brachial plexus are the 1998 study by Gaposhkin et al. ${ }^{9}$ who reported 15 patients, 11 of whom had desmoid tumors, and the experience of Ganju and associates, ${ }^{8}$ who reported six desmoid tumors out of 111 consecutive surgically treated brachial plexus tumors. Unfortunately, Ganju et al. did not comment on which patients received radiation therapy or on the interval between the initial surgery and tumor recurrence. Combining our experience and that of both Gaposhkin et al. and Ganju et al., a total of 21 cases have been reported (Table 1). The mean age of presentation among these patients is 49 years with 12 of the 21 patients being female. Fourteen of the 15 patients $(93 \%)$ for whom we have information on adjuvant thera- py received some form of radiation therapy. After a mean follow-up of 61 months, 15 of 21 patients were diseasefree while six patients were living with persistent disease. Interestingly, the one patient from our institution who is living with persistent disease had her recurrence arise outside of the field of radiation. Dying of desmoid-type fibromatosis is felt to be rare and was not reported in any of the patients in these series. ${ }^{8,9,25}$

Of the combined 21 patients from our study and others, $10(48 \%)$ had new or worsened pain after resection, and $10(48 \%)$ had new or increased upper extremity weakness. Two of 21 patients underwent forequarter amputations for recurrent tumor. Of the four patients reported in our series, the only new neurologic deficits were the three cases of hemidiaphragm paralysis. This high rate of neurological morbidity seen in this aggregate series of patients underscores the need for the treating surgeons to have expertise in working in this region of the body. It also emphasizes the importance of evaluating the risk/benefit ratio of obtaining a more extensive tumor resection at the expense of putting neurovascular structures at risk.

In addition to surgery and radiation therapy, chemotherapy, both hormonal and cytotoxic, has been used in the management of desmoid-type fibromatosis. Hormonal therapy has been explored based on the observed female predominance in this disease as well as the finding that 
some of these tumors exhibit estrogen receptors. Several reports have anecdotally confirmed a good response to treatment with tamoxifen or medroxyprogesterone acetate in combination with goserelin. ${ }^{26,28}$ In some patients in whom desmoid-type fibromatoses are not amenable to resection, cytoxic chemotherapy regimens have been employed with some success. Patients have generally been treated using a sarcoma regimen (cyclophosphamide and doxorubicin; ifosamide and etoposide; and mitomycin-C with doxorubicin and cisplatin). ${ }^{20}$

Recently imatinib mesylate has been advocated for use in these mesenchymal lesions on the basis that occasional positive immunostaining for the c-KIT (CD117) marker has been seen. This agent has been used successfully as adjuvant therapy for gastrointestinal stromal tumors, which exhibit strong immunoreactivity for c-KIT (CD117). In these tumors, the therapeutic response has been found to correlate best with $c$-KIT mutational status. ${ }^{4}$ In our series all four tumors showed weak cytoplasmic immunoreactivity to CD117 in sporadic cells. Using polymerase chain reaction we identified a single base pair change at exon 10 of the $c-K I T$ gene in three of four cases. In two tumors, a single base pair change at codon 541 (A to C) resulted in an amino acid change from methionine to leucine. In one case, a base pair change at codon 546 (A to G) resulted in no amino acid change. We cannot be sure whether these base changes represent a true mutation or a polymorphism; however, the normal frequency of the wild-type allele at this site is listed to be $99.9 \%$ on the nucleotide polymorphism database (www.ncbi.nlm.nih.gov/SNP). Although no mention is given in the database to the $\mathrm{A}$ to $\mathrm{C}$ base pair change at codon 541, Nagata et al. ${ }^{17}$ have documented that this change occurs in $9 \%$ of healthy individuals. This base pair change was also found in cases from our laboratory data base in one abdominal desmoid-type fibromatosis, one malignant melanoma, and four of 20 gastrointestinal stromal tumors. The one patient in our series who received imatimib mesylate had the $A$ to $C$ base pair change at codon 541. Unfortunately, no positive therapeutic response was noted, and the patient was subsequently switched to hormonal therapy with limited benefit. To our knowledge no other laboratory has assessed the c-KIT mutational status of desmoid-type fibromatosis.

Recently, several other advances have been made in understanding the biology of these neoplasms, including the finding of upregulation of the Wilm tumor gene 1 and high-level beta-catenen protein expression. ${ }^{1,18}$ Selective estrogen receptor modulators such as reloxifene and vitamin D3 are also being heralded as having therapeutic benefit in patients with desmoid-type fibromatosis.

\section{Conclusions}

Desmoid-type fibromatoses involving the brachial plexus are locally aggressive lesions with a high rate of recurrence even after GTR. We advocate the use of fractionated radiotherapy after resection in order to obtain optimal local control. Although there are no large studies confirming the benefit of specific chemotherapeutic drugs with regard to these lesions, several potentially beneficial agents have been identified. We believe the use of imatimib mesylate merits further investigation based on the
c-KIT oncogene abnormalities we have observed in several of these neoplasms.

\section{References}

1. Amini Nik S, Hohenstein P, Jadidizadeh A, Van Dam K, Bastidas A, Berry RL, et al: Upregulation of Wilms' tumor gene 1 (WT1) in desmoid tumors. Int J Cancer 114:202-208, 2005

2. Brennan MF, Alektiar KM, Maki RG: Soft tissue sarcoma, in DeVita VT, Hellman S, Rosenberg SA (eds): Cancer: Principles and Practice of Oncology, ed 6. Philadelphia: Lippincott Williams \& Wilkins, 2001, pp 1841-1935

3. Brooks JJ: Disorders of soft tissue, in Sternberg SS, Antonioli DA, Carter D, Mills SE, Oberman HA (eds): Diagnostic Surgical Pathology, ed 2. New York: Raven Press, 1994, pp 147-230

4. Corless CL, Fletcher JA, Heinrich MC: Biology of gastrointestinal stromal tumors. J Clin Oncol 22:3813-3825, 2004

5. Ferah Y, Ayse K, Mustafa C, Ugur S, Murat G, Lale AI: Possible therapeutic role of vitamin D3 in aggressive fibromatosis. Jpn J Clin Oncol 34:472-475, 2004

6. Fletcher CDM (ed): Diagnostic Histopathology of Tumors. New York: Churchill Livingstone, 1995, pp 1064-1065

7. Friede RL, Pollak A: Neurosurgical desmoid tumors: presentation of four cases with a review of the differential diagnoses. J Neurosurg 50:725-732, 1979

8. Ganju A, Roosen N, Kline DG, Tiel RL: Outcomes in a consecutive series of 111 surgically treated plexal tumors: a review of the experience at the Louisiana State University Health Sciences Center. J Neurosurg 95:51-60, 2001

9. Gaposhkin CG, Bilsky MH, Ginsberg R, Brennan MF: Function-sparing surgery for desmoid tumors and other lowgrade fibrosarcomas involving the brachial plexus. Neurosurgery 42:1297-1303, 1998

10. Goldblum J, Fletcher JA: Desmoid-type fibromatoses, in Fletcher CDM, Unni KK, Mertens F (eds): World Health Organization Classification of Tumours: Pathology \& Genetics of Tumours of Soft Tissue and Bone. Lyon: IARC Press, 2002, pp 83-84

11. Gonatas NK: Extra-abdominal desmoid tumors. Report of six cases. Arch Pathol 71:214-221, 1961

12. Goy BW, Lee SP, Fu YS, Selch MT, Eilber F: Treatment results of unresected or partially resected desmoid tumors. Am J Clin Oncol 21:584-590, 1998

13. Gronchi A, Casali PG, Mariani L, Lo Vullo S, Colecchia M, Lozza L, et al: Quality of surgery and outcome in extra-abdominal aggressive fibromatosis: a series of patients surgically treated at a single institution. J Clin Oncol 21:1390-1397, 2003

14. Hill DR, Newman H, Phillips TL: Radiation therapy of desmoid tumors. AJR Radiation Ther Nucl Med 117:84-89, 1973

15. Kim DH, Murovic JA, Tiel RL, Moes G, Kline DG: A series of 146 peripheral non-neural sheath nerve tumors: 30-year experience at Louisiana State University Health Sciences Center. J Neurosurg 102:256-266, 2005

16. Mitchell A, Scheithauer BW, Ebersold MJ, Forbes GS: Intracranial fibromatosis. Neurosurgery 29:123-126, 1991

17. Nagata H, Worobec AS, Metcalfe DD: Identification of a polymorphism in the transmembrane domain of the protooncogene c-kit in healthy subjects. Exp Clin Immunogenet 13:210-214, 1996

18. Ng TL, Gown AM, Barry TS, Cheang MC, Chan AK, Turbin DA, et al: Nuclear beta-catenin in mesenchymal tumors. Mod Pathol 18:68-75, 2005

19. Nuyttens JJ, Rust PF, Thomas CR Jr, Thurrisi TA III: Surgery versus radiation therapy for patients with aggressive fibromatosis or desmoid tumors: a comparative review of 22 articles. Cancer 88:1517-1523, 2000 
20. Okuno SH, Edmonson JH: Combination chemotherapy for desmoid tumors. Cancer 97:1134-1135, 2003

21. Pritchard DJ, Nascimento AG, Peterson IA: Local control of extra-abdominal desmoid tumors. J Bone Joint Surg Am 78:848-854, 1996

22. Quest DO, Salcman M: Fibromatosis presenting as a cranial mass lesion; case report. J Neurosurg 44:237-240, 1976

23. Rai AT, Nguyen TP, Hogg JP, Gabriele FJ: Aggressive fibromatosis of the head and neck in a patient with Gardner's syndrome. Neuroradiology 43:650-652, 2001

24. Rosai J (ed): Ackerman's Surgical Pathology, ed 8. St. Louis: Mosby-Year Book, 1996, pp 2021-2034

25. Seinfeld J, Kleinschmidt-Demasters BK, Tayal S, Lillehei K: Desmoid-type fibromatosis involving the brachial plexus: treatment options and assessment of $c$-KIT mutational status. J Neurosurg 104:749-756, 2006
26. Siegel NS, Bradford CR: Fibromatosis of the head and neck: a challenging lesion. Otolaryngol Head Neck Surg: 123: 269-275, 2000

27. Wang C, Chang Y, Ko J, Cheng C, Yeh C, Lou P: Desmoid tumor of the head and neck. Head Neck 28:1008-1013, 2006

28. Wilcken N, Tattersall MH: Endocrine therapy for desmoid tumors. Cancer 68:1384-1388, 1991

Manuscript submitted April 11, 2007.

Accepted April 26, 1007.

Address reprint requests to: Kevin O. Lillehei, M.D., Department of Neurosurgery, University of Colorado Health Sciences Center, Denver, Colorado 80262. email: Kevin.lillehei@UCHSC.edu. 